\title{
PASADO Y PRESENTE DE LOS USOS MEDICINALES DEL CANNABIS EN MÉXICO
}

\author{
José Domingo Schievenini* / Carlos A. Pérez Ricart**
}

\section{RESUMEN}

Este artículo tiene dos objetivos. Por un lado, examinar la historia de los usos terapéuticos y medicinales del cannabis en México; por el otro, exponer el proceso histórico que ha dado lugar a una compleja discusión sobre los usos médicos del cannabis en el México contemporáneo. La primera parte del artículo documenta la manera cómo la planta cannabis y sus derivados fueron incorporados en la farmacéutica mexicana durante el siglo XIX y principios del xx. La segunda parte expone el proceso tras el cual la planta cannabis dejó de ser considerada por los discursos oficiales un medicamento, para convertirse en una droga prohibida en el siglo xx. A la luz de esos antecedentes, la tercera sección expone de manera puntual el debate legislativo que actualmente busca reivindicar los usos medicinales del cannabis en México. Para la elaboración de este artículo se sistematizaron fuentes documentales de naturaleza diversa, las cuales fueron abordadas desde perspectivas ancladas tanto en la historia cultural e institucional, como en el debate actual de política global de drogas.



* Facultad de Psicología, Universidad Autónoma de Querétaro (UAQ). Correo electrónico: $<$ jose.schievenini@uaq.mx>.

** St. Antony’s College, Universidad de Oxford. Correo electrónico: <carlos.perezricart@ history.ox.ac.uk>. 


\section{INTRODUCCIÓN}

Es imposible comprender el presente del cannabis en México sin antes haber examinado su pasado. Por esta razón, el primer objetivo de este artículo explora el proceso histórico del uso medicinal del cannabis en México, para con ello poder comprender los antecedentes del actual estatus legal de esta planta y así desarrollar el segundo objetivo, el cual radica en contextualizar la discusión que ha emergido en los últimos años en torno a los usos medicinales y terapéuticos del cannabis en el México contemporáneo.

Como se demuestra mediante un trazado histórico que va de la primera mitad del siglo xIX a la actualidad, alrededor del cannabis y sus usos terapéuticos han circulado discursos que cristalizaron en leyes, regulaciones y decretos no siempre consecuentes con la evidencia científica disponible en su tiempo. Sin embargo, el tamaño de la brecha entre la evidencia científica disponible y la codificación legal del cannabis en México ha variado en función de distintos contextos históricos. Durante el siglo xIx y principios del $\mathrm{xx}$, la brecha entre evidencia científica y leyes no fue significativa; no obstante, en el ecuador del siglo xx creció desproporcionadamente, y todo apunta a que esta brecha ha vuelto a reducirse a comienzos del siglo XXI.

Además de esta introducción, el artículo está compuesto por tres secciones. La primera parte documenta cómo la planta cannabis y sus derivados fueron incorporados en la farmacéutica mexicana durante el XIX y principios del xx. A lo largo de este apartado se presenta evidencia del carácter neutral e incluso positivo con el cual la planta cannabis se representaba en medio de la comunidad médica, al punto de ser considerada patrimonio botánico nacional. Este primer apartado fue subdivido en varios puntos, para así lograr examinar con mayor precisión la codificación penal y sanitaria en materia de drogas durante el siglo XIX, y para lograr contrastar cómo los usos medicinales del cannabis comenzaron a ser opacados por la estigmatización a la que estuvieron expuestos los consumidores de marihuana.

La segunda parte del artículo examina cómo a principios del siglo xx los usos terapéuticos y medicinales del cannabis dejaron de reconocerse como legítimos, para subrayarse solo sus efectos nocivos, provocando su prohibición. Se hace un recorrido histórico que va desde el análisis de los fundamentos de la prohibición establecidos en la Constitución Política de 1917 -vigente hoy en día-, hasta la aplicación de diferentes leyes y decretos que ignoraron las propiedades medicinales y terapéuticas del cannabis. Durante gran parte del siglo xx, los usos medicinales de la planta no solo quedaron en el olvido, sino que su consumo fue tipificado como delito. Para ser más 
precisos, como "Delitos contra la salud": una contradicción que resulta polémica en el marco de los debates científicos y legislativos que actualmente reivindican los usos medicinales del cannabis.

La tercera parte del texto retoma el proceso histórico expuesto en las secciones previas, para así exponer el debate legislativo que actualmente busca reivindicar a través de diversos planteamientos clínicos los usos medicinales del cannabis en México. En concreto se examinan los pasos que en la última década se han dado para la regulación integral del cannabis. Una regulación que busca abordar no solo el uso medicinal, sino también el llamado uso lúdico o recreativo.

$\mathrm{Al}$ analizar con profundidad los discursos y prácticas dominantes sobre el uso medicinal del cannabis, este artículo busca hacer una contribución tanto a la historia cultural e institucional alrededor de la marihuana en México como al debate actual de política global de drogas. Se une, así, a una serie de trabajos que han buscado comprender los orígenes de la prohibición y su peso específico en las discusiones actuales. ${ }^{[1]}$ Aunque no se presenta desde una perspectiva comparada, el artículo está pensado para leerse desde una mirada que permita identificar diferencias y similitudes frente a procesos similares en América Latina, uno de los objetivos del dossier en el que se publica este texto.

Para la elaboración de este artículo se sistematizaron fuentes documentales de naturaleza diversa. La primera parte descansa en fuentes primarias relativas a la farmacéutica mexicana y global del siglo XIX, algunas de estas inéditas para este tipo de trabajos. La segunda parte, además de incluir una revisión de material hemerográfico, se nutre de documentos legales. Por último, la tercera sección rescata fuentes contemporáneas que permiten examinar el estado actual del debate sobre el presente del cannabis medicinal en México.

\section{EL USO MEDICINAL DEL CANNABIS EN EL SIGLO XIX MEXICANO}

Esta primera parte del artículo se subdivide en cuatro secciones. La primera trata las referencias al cannabis en diferentes libros recopilatorios de recetas de productos con propiedades medicinales, también conocidos como farmacopeas. La segunda presenta los principales debates médicos en torno al cannabis en la segunda mitad del siglo XIX. La tercera analiza la codificación

[1] Véanse Campos (2012), Dawson (2018), Enciso (2015), Pérez Montfort (2016), Pérez Ricart (2018), Schievenini (2018) y Smith (2016). 
penal y sanitaria de productos derivados del cannabis. Finalmente, la última parte de esta primera sección analiza las referencias a los usos medicinales del cannabis en la prensa del siglo xix.

\section{El cannabis en la Farmacopea mexicana del siglo XIX}

En 1838 fue fundada la Academia de Farmacia y en 1842 sus miembros comenzaron a escribir la Farmacopea mexicana, publicada en 1846 (Academia Farmacéutica de la Capital de la República, 1846). En la sección de "Medicinas elementales más comunes" se mencionan tanto la "cannabis índica" -que también se identificaba como "Rosa María", "cáńamo del país" y "marihuana" - como la "cannabis sativa" -que hacía referencia al "cáñamo"-. Con neutralidad farmacológica, a ambas especies se les atribuían propiedades "narcóticas"; sin embargo, llama la atención que no se mencione que la planta se consumiese fumada o inhalada. Esta farmacopea fue la culminación de varios esfuerzos que buscaron mapear el patrimonio botánico de la nación que emergía, y en ese contexto mostró cómo el género botánico cannabis, tras haber sido introducido por los españoles en territorio mexicano con tres siglos de anterioridad, ya se encontraba enraizado en varias prácticas culturales del México independiente.

En 1874, la Sociedad Farmacéutica Mexicana publicó un nuevo compendio farmacéutico (Sociedad Farmacéutica Mexicana, 1874). Al igual que en la versión de 1846 se diferenció al "cáñamo" de la "marihuana". Al primero se le identificó botánicamente como "cannabis sativa", y la "marihuana”, por su parte, fue identificada como "cannabis índica". Se especificó que en territorio mexicano ambas gozaban de distintos usos terapéuticos, pero también se precisó que solo la "cannabis índica" tenía propiedades narcóticas, señalamiento que también aparecería en las subsecuentes farmacopeas -específicamente en las de 1884 y de 1896-. La versión de 1874 de la Farmacopea mexicana fue el aval y la principal influencia para que la planta se mostrase como orgullo del patrimonio botánico nacional en la Exposición Universal de París en 1876.

En las ediciones de 1874, 1884 y 1896 de la Farmacopea mexicana, tanto "marihuana", como "cannabis índica" y "cannabis sativa" se relacionaron explícita y directamente con las propiedades medicinales de la planta incluidas las propiedades narcóticas que se mencionaban con total neutralidad farmacológica-. En cada una de esas ediciones se mantenía la distinción de las dos variedades de "marihuana", agregando que la "cannabis sativa", además de "cáñamo" se conocía como chanvre indien - "cáńamo 
Indio" en francés-y como hemp-"cáńamo"- en inglés. También se atribuía a la marihuana las propiedades de vomipurgante, diurético y tónico del corazón, además de que sus semillas trituradas y mezcladas con agua producían una emulsión que se empleaba "como emoliente en las inflamaciones de las mucosas" (Sociedad Farmacéutica Mexicana, 1874: 72). ${ }^{[2]}$

A la "cannabis índica", de acuerdo con la edición de la Farmacopea mexicana de 1874 , se le atribuían propiedades sedantes e hipnóticas, precisando que era un "narcótico poco usado en medicina" (Sociedad Farmacéutica Mexicana, 1874: 154). En un pie de página dentro de esa farmacopea se especificaba que algunos botánicos consideraban a la "cannabis índica" como una simple variedad de la "cannabis sativa" (Sociedad Farmacéutica Mexicana, 1874: 154). ${ }^{[3]}$ Las diferencias taxonómicas entre especies se documentaron con los estudios de Carlos Linneo. Por su parte, sobre las propiedades de la "cannabis índica" se cita como referencia el libro Les drogues simples d'origine vegetale (Planchon, 1895), así como los estudios de Schelinger, Siebad, Bourbelos, Bradbury, De Courtive y Personne. A estos dos últimos se les atribuía el descubrimiento de la resina verde a la que consideraron el principio activo de la planta. A esta resina o aceite esencial lo llamaron "canabina" y se especificaba que "sus propiedades y efectos en el organismo humano habían sido poco estudiadas" (Sociedad Farmacéutica Mexicana, 1896: 115).

En otra sección y de manera independiente a los usos de la "cannabis índica" y de la "cannabis sativa", la Farmacopea mexicana, en sus ediciones de 1874,1884 y 1896 reconocía las propiedades antiasmáticas de los "cigarros de marihuana". ${ }^{[4]}$ Estos usos medicinales del cannabis, como se analizará más adelante, fueron avalados por varios códigos de salubridad en México. Durante la segunda mitad del siglo xIx y hasta principios del siglo xx varios de los medicamentos y fármacos prohibidos en la actualidad se comercializaban y consumían mediante regulaciones sanitarias y no requerían de restricciones legales de corte penal.

Sobresale cómo durante las últimas décadas del siglo XIx las principales instituciones farmacéuticas en México reconocían el uso medicinal de sus-

[2] Esta referencia se mantuvo en las segunda y tercera ediciones del texto. Véanse Sociedad Farmacéutica Mexicana (1884: 41) y Sociedad Farmacéutica Mexicana (1896: 40), respectivamente.

[3] Esta caracterización se repite en las segunda y tercera ediciones del texto. Véanse Sociedad Farmacéutica Mexicana (1884: 79) y Sociedad Farmacéutica Mexicana (1896: 114), respectivamente.

[4] Véanse Sociedad Farmacéutica Mexicana (1874: 393), Sociedad Farmacéutica Mexicana (1884: 251) y Sociedad Farmacéutica Mexicana (1896: 774), respectivamente. 
tancias que eventualmente serían consideradas "drogas" prohibidas. No solo la marihuana, sino también opio, morfina, heroína, e incluso cocaína eran parte de la oferta terapéutica disponible para la sociedad mexicana. De las mencionadas, el opio fue el más empleado, se usaba en cientos de preparados; sin embargo, muchas otras recetas incluían sustancias que hoy en día se encuentran prohibidas o estrictamente fiscalizadas (Durán, 2000; Martín Martín, Valverde y De Montenegro, 1995; Ponce Alcocer, 2004).

\section{Debates médicos sobre el cannabis en el siglo XIX}

En la segunda mitad del siglo XIX referencias a la marihuana comenzaron a aparecer en contextos distintos al farmacéutico. En el sector médico se analizaba con mayor cautela el uso narcótico de la planta y en la prensa de la segunda mitad del siglo xIX se acentuaba su consumo -fumado- dentro de las clases populares en general y los sectores marginales en particular.

El registro más antiguo que explicita el acto de fumar cannabis en México data de 1853. Se trata de las Lecciones de farmacología escritas por el médico Leonardo Oliva. En esta obra se señala que "algunos mexicanos" fumaban las hojas de la planta, buscando intoxicación e ilusiones sin las irritaciones gástricas y otros efectos negativos de las bebidas alcohólicas (Oliva, 1853). Oliva, quien se desempeńaba como director del Departamento de Farmacología en la Universidad de Guadalajara, insinuó el origen indígena de la mayoría de las plantas contenidas en esa obra, sin embargo, todas las referencias relativas al cannabis provienen de autores extranjeros. Al médico británico William O’Shaughnessy, por ejemplo, lo cita al mencionar sus propiedades para tratar tétano, reumatismo, rabia, delirium tremens y cólera. $\mathrm{O}$, por poner otro ejemplo, cuando Oliva menciona las alucinaciones que provoca este consumo, hace referencia a la obra Hashish and Mental Illness, escrita en 1845 por el psiquiatra francés Jaques-Joseph Moreau.

En 1859, el médico Crescencio García publicó la obra titulada Fragmento para la materia médica mexicana. Después de emprender un viaje de varios años por la región central de México, García advirtió tanto los usos medicinales, como los lúdicos de la planta. Señaló que bajo los efectos de la marihuana "hay más propensión a las ideas alegres y uno de los efectos más constantes es el de provocar risotadas que duran todo el tiempo que se está sometido a su acción, la cual se prolonga a veces por tres o cuatro horas". En sus palabras, "fumada habitualmente y en grandes cantidades la mari- 
huana predispone a la apoplejía y embrutece el espíritu" (Ochoa Serrano, 1980: 85). Sobre las hojas de marihuana comenta que:

fumadas aun mezcladas con tabaco como la usan los árabes y aquí en la República principalmente los presidiarios de la isla de Mezcala y Cárcel de Guadalajara, se emplean para procurarse una especie de embriaguez particular acompañada de sensaciones voluptuosas en que se ve lo que no existe, se juzga de diferente modo lo que ha sido (Ochoa Serrano, 1980: 85).

No obstante los usos lúdicos y los posibles efectos negativos, García afirmaba que, en aquellas décadas de la segunda mitad del siglo xix, "la marihuana o hachisch" llamaba la atención de los médicos europeos "como agente poderoso, sobre el cual se ha escrito mucho" y enfatizaba que este interés se debía a la evidencia que mostraba cómo la planta "cura un gran número de enfermedades" (Ochoa Serrano, 1980: 85).

Crescencio García parafraseaba a Jaques-Joseph Moreau al afirmar que esta planta ha sido llamada "a prestar grandes servicios en la patología mental y en las neurosis en general”. Aseveraba que los médicos árabes y británicos eran los que más prescribían la marihuana y la recomendaban "contra la epilepsia, tétanos y convulsiones de los niños", así como en casos de "hidrofobia y reumatismo articular" (Ochoa Serrano, 1980: 85). Además, enfatizaba los beneficios de esta planta para ayudar en los partos complicados, disminuyendo "las contracciones uterinas" y obrando como "sedativa de los dolores". García afirmaba que dentro de los usos y las costumbres farmacéuticas en México también se usaba la "tintura de cannabina" en infusión de manzanilla para tratar el cólera. Por otra parte, las hojas de la planta, mezcladas en manteca formando un ungüento, ayudaban a tratar las hemorroides. El "extracto de marihuana" mezclado con "lupulina" se recomendaba como bebida antes de dormir pues era muy útil -escribía García- contra la amenorrea en el caso de las mujeres, y en los hombres evitaba las erecciones nocturnas. Para la elaboración de otros preparados, heredados de la farmacopea francesa, inglesa o árabe, la "canabina" o "hachichina" se mezclaba con éter, jarabe de canela, esencia de menta, cloroformo, aceite vegetal o azúcar.

Sin embargo, como lo demuestra el siguiente caso, hacia la segunda mitad del siglo XIx no todas las voces dentro del ámbito científico percibían a la marihuana con neutralidad farmacológica. En una investigación pionera en México titulada "La marihuana. Breve estudio sobre esta planta", escrita en 1886, su autor, el médico Genaro Pérez, concluyó que a pesar de que la planta gozaba de diversos usos terapéuticos -reconocía que ayudaba 
para tratar trastornos de estómago, cefalea y asma; en emulsión de semillas para la irritación de las vías urinarias y para curar la galactorrea y blenorragia; así como el extracto de "canabina" para la neurosis, y el aceite para uso tópico en caso de hemorroides-, también podía provocar trastornos mentales identificados por alucinaciones (Pérez, 1886).

Muchas de las observaciones plasmadas en la investigación de Genaro Pérez provenían de experiencias recabadas dentro del Hospital Militar y del Hospital de San Hipólito, lugares donde se realizaron entrevistas a varios individuos que fumaban marihuana, a quienes llamó "viciosos". Pérez concluyó que el consumo de marihuana -a pesar de sus beneficios terapéuticos- podía desencadenar patologías alucinatorias enmarcadas en el espectro de lo que él llamó "lipemanía por abuso de marihuana".

Una visión algo más balanceada la presenta el Curso de historia de drogas, obra escrita por el galeno Juan Manuel Noriega y publicada por el Instituto Médico Nacional en 1902. En esta publicación se reconocían los usos medicinales de la marihuana, enumerando las distintas preparaciones farmacéuticas disponibles en México. Según esta publicación, las preparaciones más comunes realizadas con derivados del cannabis eran: tintura y extracto alcohólico; "haschischina o canabina morena de Smith, preparación muy activa que se emplea a la dosis de 3 a 5 centigramos"; "resina verde o canabina verde, menos activa y empleada a la dosis de 5 a 10 centigramos"; "el extracto graso obtenido haciendo disolver la canabina verde en la manteca, empleada a la dosis de 2 a 4 gramos" y "la tintura de canabina y el extracto etéreo de marihuana constituido en gran parte por canabina verde" (Noriega, 1902: 220).

Sobre el uso de la marihuana en el sector médico, en esta obra se puede leer que "su verdadera acción fisiológica es bastante mal conocida y las experiencias científicas, las únicas que tienen un valor real, son poco numerosas; de allí la dificultad de formarse una idea exacta de los fenómenos producidos". El texto enfatiza que es indiscutible "y desde hace largo tiempo puesto fuera de duda", el hecho de que la marihuana coloca a los usuarios consuetudinarios en un "estado de embrutecimiento y muchas veces de locura" (Noriega, 1902: 220).

Con el pasar de los años comenzaron a ser más frecuentes los textos donde la élite médica y algunos miembros de instituciones gubernamentales despreciaban la marihuana por identificar su consumo "narcótico" dentro de los hábitos de la población indígena y dentro de ambientes urbanos marginales - prisiones, filas del ejército, mercados y tugurios-. Aunque se trató de un fenómeno social de magnitud insignificante en comparación con lo que representaba en aquel entonces la ingesta de bebidas alcohólicas, 
su estigmatización tomaría dimensiones aun difíciles de comprender desde la perspectiva historiográfica contemporánea. A partir de las últimas décadas del siglo XIX, ambos consumos - de bebidas alcohólicas y de marihuana- serían consideradas un vicio. Sin embargo, en el caso del alcohol solamente se consideraba vicio cuando se abusaba de él y cuando se incurría en conductas escandalosas; en contraposición, el uso de marihuana comenzó a considerarse una conducta viciosa en cualquier contexto en el que apareciera (Schievenini, 2018).

\section{La codificación penal y sanitaria en el siglo XIX}

El Código Penal Federal de 1871 fue el primer ordenamiento que en México tipificó los "Delitos contra la salud pública" (Gobierno de México, 1871). Sin embargo, como se mostrará a continuación, contrario a lo que sucedería en el siglo xx, el uso de drogas no se castigaba penalmente. En los artículos referentes a los "Delitos contra la salud pública" estipulados en el Código Penal de 1871, de acuerdo a lo establecido en el artículo 843, se castigaba hasta con cuatro meses de arresto a quien "sin autorización legal elabore para venderlas sustancias nocivas a la salud y aquellos productos químicos que puedan causar grandes estragos" (Gobierno de México, 1871). En el artículo 844, se estipulaba multa y una pena significativamente más alta -que podía ser hasta de dos años de prisión-a los boticarios y comerciantes de drogas que falsificaran o adulteraran medicinas (Gobierno de México, 1871). En caso de que el "reo condenado" fuese comerciante, expendedor de droga o boticario, en el artículo 852 se establecía que la sentencia condenatoria debía publicarse en los periódicos del lugar y además debía fijarse en la puerta de la tienda o casa donde se hizo la venta (Gobierno de México, 1871). En tanto que, según lo dispuesto en el artículo 851, se castigaba también -con hasta tres años de prisión-a quien envenenara depósitos de agua potable o productos comestibles (Gobierno de México, 1871).

Al evitar la adulteración y el menoscabo de la calidad de las sustancias, las sanciones contenidas en el Código Penal de 1871 buscaban evitar la afectación de un bien jurídico específico: la salud de los consumidores $-\mathrm{y}$, por ende, la salud pública-. En esta ley aún no se hablaba de drogas enervantes, de sustancias y plantas que degeneran la raza, de narcóticos, psicotrópicos y estupefacientes; tampoco de toxicomanías y toxicómanos como lo harían varios ordenamientos a partir de las primeras décadas del siglo xx. Por el contrario, en este Código Penal se hablaba de "sustancias nocivas para 
la salud pública", las cuales podían ser productos químicos y sustancias contenidas en alimentos, bebidas o medicinas. El consumo de cualquier sustancia-medicinal o no-, si bien era regulado por los Códigos de Salubridad -de 1891, 1894 y 1902-, aún no preocupaba al sistema penal mexicano. Ni el Código Penal de 1871 ni los mencionados Códigos de Salubridad buscaban combatir el consumo o la existencia de las drogas en sí. Al regular y velar por la pureza y calidad de las sustancias que ingresarían al organismo humano, esos ordenamientos tutelaban una salubridad pública que descansaba en la salud de los consumidores.

De forma simultánea a la vigencia del Código Penal Federal de 1871 -que fue derogado hasta 1929-, la producción, comercio y consumo de sustancias, fármacos, drogas o medicamentos fue regulada por los Códigos de Salubridad de 1891, 1894 y 1902. En estas tres leyes fueron reconocidos los usos medicinales de varias drogas, entre ellas: marihuana, cicuta, belladona, falso estramonio o toloache, nicotina, cloroformo, cocaína, codeína, ergotina, estramonio, opio, morfina, extracto de adormidera, cafeína y ácido salić́lico, protegiendo así la salud de quien necesitase estos productos con objetivos terapéuticos, siempre y cuando no perjudicase a terceros. Al velar por la calidad de los productos farmacológicos consumidos se buscaba evitar, efectivamente, la vulneración de la salud pública.

En el artículo 210 del Código Sanitario de 1902 -que tendría vigencia hasta 1926- se incluía la "canabina" en la "lista de sustancias que aisladamente o en cualquier forma farmacéutica, solo podrán venderse por prescripción médica o a petición o con sello". En tanto que en el artículo 212 se detallaba la "lista de las dosis máximas de las sustancias que pueden despachar los farmacéuticos a un adulto en una toma o en 24 horas" se enumera el "tanato de canabina" -la dosis permitida a la venta era de medio gramo a uno y medio-; el "extracto alcohólico de cannabis" - de un miligramo a medio gramo-; la "canabinona" -de uno a tres miligramos- y la "tintura de haschich" - de cinco miligramos a dos gramos-. Asimismo, en el artículo 217 se contemplaba una "lista de las sustancias, preparaciones, utensilios y aparatos de los que deberán estar provistas las boticas". En esta lista aparecen, entre otras sustancias, cafeína, cocaína, codeína, ergotina, morfina, elixir y vino de coca, polvos de Dover, opio en jugo concentrado, "extracto de cannabis índica" y "semillas de cáñamo" (Secretaría de Gobernación de México, 1903). Las semillas de cáńamo eran recomendadas por boticarios como emoliente para tratar la gonorrea, la "disuria inflamatoria” y para expulsar cálculos vesicales (Durán, 2000).

Por último, con respecto al Código de Salubridad de 1902, en el artículo 209 resalta que la "marihuana" aún se contemplaba dentro de la "lista 
de las plantas y animales medicinales que los colectores solo pueden vender a los farmacéuticos y droguistas" (Secretaría de Gobernación de México, 1903). Hasta ese punto, ya en los primeros años del siglo xx, la legislación mexicana abordaba en toda su complejidad una planta con propiedades farmacológicas tan variadas y reconocía como legítimo el uso medicinal del cannabis.

\section{El uso medicinal del cannabis en la prensa del siglo XIX}

El registro hemerográfico más antiguo con el cual se puede rastrear una caracterización negativa de la marihuana proviene del periódico El Republicano. En su edición del 5 de abril de 1846 el diario publicaba: "El uso de una yerba conocida con el nombre de marihuana, que los soldados fumaban como el tabaco, era la causa de esa rara enfermedad". La nota refería a una supuesta epidemia en la cual los individuos en cuestión se encontraban "sin fuerzas, lánguidos, aturdidos". Se especificaba que la marihuana era una "planta dioica, de la familia de las urticacias; una especie de cáńamo tan nocivo probablemente como el de la India" (Durán, 1846: 1). Es de resaltar que esta nota fuese publicada el mismo año en que la palabra "marihuana" fue mencionada en la primera Farmacopea mexicana de 1846, referida páginas atrás.

La primera referencia que caracterizaba negativamente al cannabis contrasta con los anuncios que, ya desde la década de 1860, lo publicitaban con fines medicinales en la prensa de la Ciudad de México. En esta publicidad se anunciaban los "Cigarros indios de cannabis índica", comercializados por Grimault y Cia, Farmacéuticos en París. En cada uno de los anuncios se incluía un pequeño texto donde se explicaba que el uso medicinal del cannabis estaba avalado por "Recientes experiencias, hechas en Viena y en Berlín, repetidas por la mayor parte de los médicos alemanes y confirmadas por las notabilidades médicas de Francia y de Inglaterra”. Esta publicidad precisaba que "bajo la forma de cigarrillos, el Cannabis indica o cáńamo indio era un específico de los más seguros contra el Asma, la Opresión, las Sofocaciones, las Bronquitis, la Ronquera, la Extinción de la voz, la Tisis pulmonar, las Laringitis, así como en todas las enfermedades de las vías de respiración" (El Siglo Diez y Nueve, 1867a). ${ }^{[5]}$

[5] En cursivas en el original. Véase también El Siglo Diez y Nueve (1867b, 1867c, 1867d, 1868, 1869) y La Sociedad (1867a, 1867b, 1867c y 1867d). 
En otras publicaciones de finales del siglo XIX -e incluso de las primeras dos décadas del $\mathrm{xx}$ - se podía leer que el extracto y la tintura de "cáńamo indio" o de "cannabis índica" poseía todas las propiedades terapéuticas de la planta, pero con "la ventaja de producir una sensación psíquica menos intensa" (La Medicina Científica, 1895: 383). Se mencionaba que existía un extracto de cannabis eficaz para tratar la gripa intestinal (Monin, 1922) y aplicándolo por la mañana y noche durante cuatro días para eliminar cualquier tipo de callo (El Consultor, 1898; El Heraldo de México, 1919 y Monnet, 1893). La tintura de cannabis solía usarse como calmante, mezclándose con agua azucarada, tomando diez gotas cada dos horas (Elegancia, 1925) y se usaba también para combatir "la tos de los tísicos" y "los estados dispépticos asociados a la constipación". Asimismo, se utilizaba como un remedio "muy útil en el tratamiento de los trastornos nerviosos en los niños" (La Medicina Científica, 1895: 383).

Sobre los efectos antiasmáticos de los "cigarros de marihuana" -los cuales, como se citó anteriormente, se publicitaban desde la década de 1860-, varias otras notas fueron encontradas en el El Diario y en El Imparcial ya durante los primeros ańos del siglo xx (El Diario, 1908a, 1908b; El Imparcial, 1908a, 1908b, 1908c). Estas publicaciones, es importante notarlo, se constituían como una excepción dentro de las notas que en los periódicos nacionales, conforme se acercaba el inicio del siglo xx, descalificaban el consumo de marihuana relacionándolo ya no solo con soldados "lánguidos, aturdidos", como lo hacía la nota del diario El Republicano de 1846 (Durán, 1846), sino que ya vinculaban a esta planta sistemáticamente con la locura y la violencia (Campos, 2012). En estas notas de corte abiertamente sensacionalista, los usos medicinales fueron ignorados de manera abrupta. Relacionada con las clases bajas, con lo indígena, con lo irracional y con algunos escenarios trágicos o sangrientos, sin duda la marihuana gozaba del potencial necesario para estar presente en la nota roja (Schievenini, 2018).

La prensa y los sectores cercanos a las élites gubernamentales durante la dictadura porfirista (1876-1911) percibieron el uso de marihuana como un problema conductual de sectores específicos de la sociedad mexicana. Este consumo, propio de los sectores desfavorecidos, ya era una preocupación que rebasaba la simple nota roja. En 1897, por ejemplo, en la revista médica La Farmacia, se afirmaba que "el cáńamo indio, o Rosa María o marihuana, enerva, produce alucinaciones halagüeñas, expansión de ánimo, turbulencia que tiende después a la exaltación y al delirio impulsivo" y se concluye que en otras regiones del planeta "el delirio que determina la marihuana es turbulento, pero en nuestro país llega 
al furor, á la impulsión terrible y ciega que conduce al asesinato" (Olvera, 1897: 269).

El embrutecimiento y los supuestos casos de locura tras consumir marihuana -los cuales fueron desplegados por la prensa de manera constante entre 1860 y 1920, y en revistas especializadas a partir de ese artículo en $\mathrm{La}$ Farmacia de 1897- son factores fundamentales para comprender la paulatina desestimación de los indiscutibles usos medicinales de la planta y para entender la génesis de su prohibición. Sobre esta prohibición, consolidada a nivel nacional en la primera mitad del siglo xx, gira la segunda sección de este artículo.

\section{LA PROHIBICIÓN DEL USO MEDICINAL DE LA MARIHUANA A PRINCIPIOS DEL SIGLO XX}

El comercio de marihuana fue restringido legalmente en varias localidades de la República Mexicana durante las últimas décadas del siglo XIx y principios del xx (Campos, 2012; Schievenini, 2018). Su venta solamente se permitía cumpliendo los requisitos farmacéuticos establecidos por el Código Penal de 1871 y por los Códigos Sanitarios de 1891, 1894 y 1902. En ese contexto regulatorio -que comenzaría a evidenciar una tendencia hacía la prohibición y la criminalización- inició un nuevo capítulo en la historia del cannabis en México.

Las primeras décadas del siglo xx fueron marcadas por la irrupción de la Revolución Mexicana, un acontecimiento que llevó, entre otras cosas, a la celebración del Congreso Constituyente de 1916-1917, del cual emergió la Constitución Política hoy todavía vigente. En aquel Congreso Constituyente se celebraron debates que apuntalaron una concepción prohibicionista de algunas drogas, así como la predominancia del Departamento de Salubridad Pública sobre asuntos sanitarios en todo el país (Agostoni, 2003; Rodríguez de Romo y Rodríguez Pérez, 1998). En una de las primeras sesiones del Constituyente, el diputado José María Rodríguez, futuro presidente del Consejo Superior de Salubridad, afirmó que "como la degeneración de la raza mexicana es un hecho demostrado también por los datos estadísticos", era necesario tomar medidas en torno al uso de opio, morfina, éter, cocaína, y marihuana. ${ }^{[6]}$ Rodríguez equiparaba el consumo de esas

[6] Véase Comisión Nacional para la Celebración del Sesquicentenario de la Proclamación de la Independencia Nacional y del Cincuentenario de la Revolución Mexicana (1960). 
drogas con el peligro derivado de epidemias que habían azotado al país en décadas anteriores, como la peste bubónica en Michoacán y Sinaloa, la fiebre amarilla en Nuevo León y Tamaulipas, así como meningitis y cólera en otros estados de la República.

A partir del discurso de Rodríguez, las directrices gubernamentales esbozaban una idea de salud pública preocupada por la existencia de algunas drogas, para evitar así la "degeneración de la raza". Esta línea de opinión se reflejó en el texto de la Constitución Política de 1917, donde se plasmaron las preocupaciones con respecto a los daños a la salud que la producción, venta y consumo de algunas drogas pudiese provocar. La misma opinión siguió reflejándose en ordenamientos legales posteriores promulgados a lo largo del siglo xx, los cuales fueron congruentes con la posición constitucional y con el carácter conservador del régimen posrevolucionario.

De 1917 en adelante los argumentos que en el ámbito médico-legal y en la prensa señalaron desde finales del siglo xix los efectos negativos de algunas sustancias, así como la vinculación de la idea de degeneración racial con los así llamados "vicios", se plasmaron en varias leyes de aplicación nacional. Asimismo, los efectos benignos del cannabis fueron dejados de lado, en la misma forma en que lo hicieron las primeras convenciones internacionales para el control de de narcóticos, a las cuales, por cierto, los representantes diplomáticos mexicanos asistieron de manera puntual desde 1912.

\section{La codificación penal en el siglo $x x$}

En marzo de 1920, el Diario Oficial de la Federación publicó las "Disposiciones sobre el comercio de productos que pueden ser utilizados para fomentar vicios que degeneren la raza y sobre el cultivo de plantas que pueden ser empleadas con el mismo fin" (Departamento de Salubridad Pública de México, 1920). Llama la atención que este decreto denomina "sustancias que degeneren la raza" a ciertos medicamentos contemplados por el Código de Salubridad vigente en ese momento, es decir, el de 1902. Si bien opio, morfina, codeína y heroína seguían siendo considerados medicamentos, y podían ser importados incluso por particulares, siempre y cuando se obtuviera el correspondiente "permiso del Departamento de Salubridad", sobre ellos se puso el calificativo de poder "degenerar la raza" (Departamento de Salubridad Pública de México, 1920).

Con los permisos correspondientes, el opio incluso podía cultivarse en territorio mexicano, no obstante la preocupación que este había despertado 
a nivel mundial durante las primeras dos décadas del siglo $\mathrm{xx}$, y a pesar de la presión del gobierno de los Estados Unidos para que México tomara medidas orientadas a evitar su contrabando, de las que se tiene registro al menos desde 1916 (Schievenini, 2018). Pero, con respecto a la marihuana, destaca que fue la única de las sustancias enlistadas que fue excluida como objeto de regulación medicinal. Independientemente de los fines con los que se consumiera, en la fracción quinta de esta disposición de 1920 se puede leer: "Queda estrictamente prohibido el cultivo y comercio de la marihuana” (Departamento de Salubridad Pública de México, 1920: 1189). Esta fracción resulta sorprendente, entre otras razones, porque el uso médico de la planta cannabis y de varios de sus derivados estaba permitido por el Código de Salubridad de 1902, vigente en ese momento.

Al prohibir la marihuana a nivel federal, el Estado mexicano olvidaría su intención -plasmada en el Código Penal Federal de 1871, también vigente en ese momento- de tutelar la salud de los consumidores regulando la producción y venta de sustancias. Se trata, así, de un punto coyuntural en la historia del cannabis en México.

Seis años después, en junio de 1926, se promulgó un nuevo Código Sanitario (Departamento de Salubridad Pública de México, 1926a, 1926b), sustituyendo así al de 1902 -que aún reconocía los usos medicinales de marihuana, "hachich", "canabina", entre otras sustancias que después serían catalogadas como drogas prohibidas y cuyo consumo sería considerado una patología y/o un delito-. En el artículo 198 de este Código Sanitario de 1926 se incluyó una lista de sustancias que serían consideradas "drogas enervantes". La lista coincidía con las drogas objeto de control establecidas en las convenciones internacionales de 1912 y 1925: opio, morfina, cocaína, heroína, adormideras, hojas de coca, "marihuana en cualquiera de sus formas [y] los preparados que contengan alguna de las sustancias, señaladas anteriormente" (Departamento de Salubridad Pública de México, 1926a: 592). En el artículo siguiente se especificaba que sería el Consejo de Salubridad la entidad que podría "ampliar la enumeración [...] incluyendo aquellas sustancias que, a su juicio, deban ser comprendidas en la categoría de drogas enervantes, por descubrirse que tienen propiedades análogas y que, usándose viciosamente, envenenan al individuo o degeneran la raza" (Departamento de Salubridad Pública de México, 1926a: 592). En este sentido, el artículo 200 del Código Sanitario de 1926 precisaba la prohibición en todo el país de la "la importación, exportación, elaboración, posesión, el uso y consumo [de] marihuana en cualquiera de sus formas (extracto de cannabis índica)", y en el artículo 202 se agregaba que "Queda prohibido en la República Mexicana el cultivo de la marihuana" (Departamento de 
Salubridad Pública de México, 1926a: 592). Meses antes de la promulgación de ése Código Sanitario de 1926 se había celebrado la Convención de Ginebra de 1925, en la cual se prohibió a nivel global el "cáñamo indio". Como se ve, México no estaba al margen de la tendencia mundial.

En 1929 y 1931 se promulgaron dos nuevos Códigos Penales Federales -que derogaron al de 1871-. En ellos, la intención legislativa abordaba al consumidor de drogas enervantes ya no regulando administrativa y farmacéuticamente las sustancias que usaba, sino confrontando al consumidor, o bien con el tratamiento que requiere una condición patológica, o bien con el castigo penal que amerita un crimen. En ambos casos, la criminalización y/o la patologización del usuario de marihuana ocurría sin importar que ese consumo fuese con fines medicinales, recreativos, de carácter problemático o no problemático.

En lo relativo a los "Delitos contra la salud", el Código de 1931 expresó de forma más precisa lo planteado por el Código Penal de 1929 en torno a las sanciones penales que debían imponerse al consumidor de marihuana. La relativa solidez jurídica de este ordenamiento al abordar el tema de las drogas radicó en su relación complementaria con el Reglamento Federal de Toxicomanía -también de 1931-, disposición que no existió cuando se promulgó el Código Penal de 1929, y que establecía con mayor claridad en qué supuestos el Estado mexicano debía considerar al consumidor de "drogas enervantes" un enfermo que requería atención y en qué casos un criminal. Dejando en el completo olvido el legítimo reconocimiento de los usos medicinales del cannabis propio del siglo XIX, ninguno de estos ordenamientos contempló la posibilidad de una marihuana con potencial clínico o terapéutico.

Con varias reformas, actualmente el Código Penal Federal de 1931 se mantiene vigente. Con tintes aún más represivos, en 1947 se modificaron algunos de sus artículos concernientes a los "Delitos contra la salud" (Meza Fonseca y Lara González, 2001). En esta reforma se sostiene el desprecio por los usos médicos y farmacéuticos del cannabis y se mantiene el lenguaje sobre "las sustancias que envenenan al individuo y degeneran la raza" (Secretaría de Gobernación de México, 1947: 3). La reforma de 1968 es igualmente prohibitiva: en ella se establece pena de dos a nueve años y multa de mil a diez mil pesos por siembra, cultivo, cosecha o posesión con cualquier fin de "cannabis resinosas" (Secretaría de Gobernación de México, 1968). Una eventual reforma de 1974 mantuvo la criminalización de cualquier uso, médico o recreativo, de la marihuana; pero para calificar a sus consumidores eliminó en el artículo 195 del Código Penal la nomenclatura de "toxicómano" e introdujo la de "adicto" (Secretaría de Salubridad y 
Asistencia de México, 1974). Más adelante, dentro de una reforma en 1978, se señaló que el consumo del "adicto" no se sanciona si la suya es una dosis personal y de consumo inmediato; sin embargo, arrastrando la ambigüedad en materia de "Delitos contra la salud" establecida en Código Penal de 1931, si a criterio de la autoridad el detenido no era una consumidoradicto, sino más bien un simple usuario-poseedor de la droga, este debería cumplir entre dos meses y ocho años de prisión (Secretaría de Gobernación de México, 1978). En este sentido, se impusieron también penas de hasta ocho años a quien cultivase "plantas de cannabis y marihuana", incluso cuando "en él concurran escasa instrucción y extrema necesidad económica” (Secretaría de Gobernación de México, 1978). Subsecuentes reformas -de 1989 y 1994 - no modificaron la desproporcionalidad en las penas aplicadas y siguieron avalando la criminalización del uso medicinal y recreativo del cannabis, calificando esos usos como "Delito contra la salud". ${ }^{[7]} \mathrm{La}$ ambigua tipificación de ese tipo penal y la desproporcionalidad en su sanción, como se ve, fueron una constante en el México del siglo Xx.

\section{La discusión médica sobre el cannabis en el siglo Xx}

La discusión científica sobre los usos medicinales del cannabis en el siglo Xx fue infértil, especialmente si se le compara con la discusión que sobre este tema existió en el siglo XIX. Los saberes médicos no estuvieron exentos de la influencia que ejercía el híbrido discursivo conformado con componentes degeneracionistas e higienistas, y en ese contexto aceptaron de manera por demás abnegada la criminalización de cualquier uso de la marihuana.

Junto a las prohibiciones de la década de 1920 destacan las opiniones de los médicos Gregorio Oneto Barenque e Ignacio Guzmán, cuyas contribuciones al debate público, siempre desde una pretendida "medicina científica", buscaban mostrar el vínculo entre drogas enervantes y degeneración. En ese marco, a finales de 1930 y principios de 1940 se publicaron varios textos sobre el cannabis en revistas de circulación nacional -Gaceta Médica Nacional, Criminalia y La Farmacia- que no reconocían las propiedades médicas y terapéuticas del cannabis (Schievenini, 2018). Las pocas voces que se opusieron a ese discurso en las primeras décadas del siglo $\mathrm{xx}$-muy notablemente la del médico duranguense Leopoldo Salazar Viniegra- fueron lentamente desplazadas de los discursos dominantes de la época (Smith, 2019).

[7] Véase también la nota 533 en Carrancá y Rivas y Carrancá y Trujillo (1976). 
Como parte de un discurso civilizatorio que encontraba paralelismos a nivel internacional y en función de lo que ocurría tras la Primera Guerra Mundial, los debates médicos dejaron de lado lo que consideraban tradiciones primitivas de curanderos y yerberos (Agostoni, 1999). Se afianzó y se utilizó la "medicina científica" para establecer las coordenadas sobre las que se desarrollaría una serie de estrategias políticas de salud que denotaron racismo y clasismo (Aréchiga Córdoba, 2007). Después de la década de 1930 y hasta inicios del siglo XXI no solo reinó cierta unanimidad con respecto al desprestigio de los usos terapéuticos y médicos del cannabis, sino que el debate apenas existió en revistas y foros especializados. Desde la criminalización del uso medicinal del cannabis a partir del Código Sanitario de 1926 y de los Códigos Penales de 1929 y 1931, y tras el breve debate acaecido a finales de la década de 1930, solamente unos cuantos artículos aislados aparecieron con respecto a las toxicomanías y al tráfico de drogas. Aparecieron, más bien, bastantes sobre el alcoholismo, y varios más que reivindicaban la defensa social y las ideas degeneracionistas e higienistas para castigar los "Delitos contra la salud" (Schievenini, 2018).

En este punto cabe preguntarse si la prohibición de los usos medicinales del cannabis en México y la falta de un debate científico fueron resultado de una tendencia marcada por el contexto internacional -incluyendo la emergencia del Régimen Global de Prohibición y la presión bilateral de los Estados Unidos- o si se trató de una decisión autónoma por parte de las élites gobernantes en el México posrevolucionario. ${ }^{[8]}$ Tomando en cuenta el desarrollo de posiciones similares en toda la región, la respuesta no puede ser binaria: el proceso de prohibición de los usos terapéuticos y medicinales del cannabis se alimentó tanto de la tendencia marcada por las convenciones internacionales en materia de drogas, como por el conservadurismo dominante en las élites gubernamentales mexicanas, las cuales se vieron envueltas en una dinámica estructural de la que resultaba difícil -acaso imposible- escapar.

El vacío de debate científico en torno al cannabis muestra cómo la sistemática criminalización de sus usuarios fue determinante en la estructuración discursiva del prohibicionismo en México. En los ámbitos legales y científicos se asumía que la marihuana evidenciaba un aura de criminalidad y que por sí misma representaba el cuerpo de un delito grave. En ese contexto, el debate sobre el uso medicinal del cannabis se extravió por completo. Si bien ciertas discusiones sobre el uso recreativo se retomaron a finales de la década de 1960 y principios de la siguiente, cuando el consumo de

[8] Sobre esta discusión, véase Pérez Ricart (2018). 
esta planta se hizo cada vez más evidente entre la juventud mexicana, la discusión sobre su uso medicinal fue prácticamente inexistente (Schievenini, 2018). Sería hasta los primeros años del siglo xxi cuando la discusión clínica sobre el cannabis y su potencial médico y terapéutico aparecería en la agenda pública nacional.

\section{EL PRESENTE DEL CANNABIS EN MÉXICO}

$\mathrm{Al}$ igual que en el resto del continente americano, en México el paradigma de la prohibición del cannabis ha ido desmontándose lentamente en la última década (Corona Ojeda, 2019). Se trata de un proceso complejo, repleto de rupturas y continuidades, pero que apunta en una misma dirección: el reconocimiento de las propiedades terapéuticas y medicinales de esta planta. En México en particular, la discusión sobre el uso medicinal del cannabis y sobre la legalización de la marihuana se ha dado en el ámbito de los tres poderes que, de acuerdo con la Constitución Política, conforman al Estado mexicano: el Poder Ejecutivo, el Poder Legislativo y el Poder Judicial.

Dentro del terreno del Poder Legislativo, tan solo en la última década se han presentado ante el Congreso más de setenta iniciativas alrededor de la marihuana; 16 de estas han sido presentadas en los últimos tres años (Senado de la República de México, 2020). Aunque algunas de ellas fueron desechadas desde su origen, otras continúan pendientes y unas pocas más han sido aprobadas con algunas modificaciones.

Por su parte, en el terreno del Poder judicial, la Suprema Corte de Justicia de la Nación ha sido -en yuxtaposición con el papel que han jugado entidades similares en otros países (Pérez Ricart, en prensa) - una fuerza liberal en lo que refiere a la ruptura del paradigma prohibicionista. Finalmente, sin tanta fuerza como el resto de los poderes, desde el Poder Ejecutivo se han dado pasos -acaso tibios e insuficientes ante la coyuntura- en favor de una discusión más abierta en torno a las drogas.

En el año 2006, el entonces presidente Vicente Fox propuso al Poder Legislativo un proyecto de ley que descriminalizara la posesión de pequeñas cantidades de sustancias prohibidas. El proyecto suponía reformas importantes a la Ley General de Salud y al Código Penal Federal, y en el caso de la marihuana permitía cinco gramos como dosis máxima de portación. A pesar de que tanto la Cámara de Diputados como la de Senadores votaron en favor del proyecto, el presidente detuvo sorpresivamente todo el proceso que él mismo había iniciado (Corona Ojeda, 2019). Tal acción solo puede 
ser explicada por la presión estadounidense a la que aparentemente fue sometido el entonces presidente (Herrera, 2006).

En los siguientes años fueron propuestas varias iniciativas de ley que iban en la misma dirección que aquella presentada en 2006 por el presidente Vicente Fox. Una de ellas, en 2007, recogía la demanda del "derecho al acceso seguro y legal para aquellas personas cuya condición de salud requiera el uso de la marihuana” (Conde Rodríguez, 2007). En la iniciativa se reconocía la utilidad del cannabis para aliviar males relacionados con trastornos neurológicos, así como para la "esclerosis múltiple, la amiotrofia lateral, la epilepsia, el síndrome de Gilles de la Tourette y muchas otras patologías neurológicas y afines a este sistema”. Aunque la iniciativa fue turnada a la Comisión de Justicia para su revisión, sin explicación alguna esta no prosperó, dejando en el aire el derecho a la salud de un número considerable de ciudadanos mexicanos.

Tres años después, en agosto de 2009 fue aprobada la llamada Ley contra el Narcomenudeo, misma que descriminalizó parcialmente el consumo personal. En concreto, se adicionó a la Ley General de Salud una tabla orientativa de dosis máximas de "consumo personal e inmediato" de ciertas sustancias, incluyendo opio, heroína, marihuana, cocaína, LSD y metanfetamina -capítulo 479, capítulo viI-. En el caso de la "cannabis sativa, índica o marihuana” se estableció un límite de cinco gramos, retomando la propuesta del titular del Poder Ejecutivo, Vicente Fox, presentada tres años atrás. Estos cinco gramos podrían usarse con fines médicos o recreativos, aunque la obtención del producto debía hacerse en el mercado ilegal, orillando al usuario a delinquir incluso cuando la obtención del cannabis estuviese destinado a tratar un padecimiento. A pesar de sus avances, los críticos de la nueva ley subrayaron que el umbral de consumo establecido era sensiblemente menor en comparación con el de otros países del continente, lo cual seguía permitiendo la criminalización de consumidores (Pérez Correa, Uprimny y Chaparro, 2016). ${ }^{[9]}$

Entre la aprobación de aquella Ley contra el Narcomenudeo de 2009 y el presente, se han acumulado varias iniciativas relativas a la relegitimización del uso medicinal del cannabis y a la descriminalización de la marihuana en general (Senado de la República de México, 2020). Estas iniciativas tenían en común ser promovidas por legisladores pertenecientes a bancadas minoritarias y sin respaldo suficiente para ser aprobadas. Sin embargo, si la inercia legislativa arrastrada desde la primera mitad del siglo xx cerró la puerta al uso médico del cannabis, otras ventanas comenzaron

[9] Para una crítica sobre el proceso de aplicación de la ley, véase Pérez Correa (2013). 
a abrirse en la segunda década del siglo xx. Tres acontecimientos cambiaron radicalmente las perspectivas para una reconfiguración de las políticas de drogas relativas al uso medicinal en particular y a la regulación de la marihuana en general.

En primer lugar, está el caso de la nińa Grace Elizalde Benavides, quien en el 2015 tenía ocho años y quien sufre del Síndrome de Lennox-Gastaut, una forma de epilepsia infantil. Ante la evidencia de que el Cannabidiol (CBD) tendría efectos positivos en su tratamiento, en ese ańo 2015 los padres de Grace iniciaron una campaña legal para importar a México el СвD. En abril de 2016, un juez federal concedió el permiso a los padres y al médico dispuesto a escribir la receta médica -requisito para obtener el permiso de importación-. A pesar de que la decisión del juez fue impugnada por algunas autoridades mexicanas, en septiembre de 2016 la Comisión Federal para la Protección contra Riesgos Sanitarios - un órgano desconcentrado de la Secretaría de Salud-concedió la autorización para la importación del producto. Desde entonces y hasta abril de 2018 se habían emitido 331 permisos para la importación de medicamentos fabricados a partir de cannabis (Muñoz, 2018). La autorización del uso medicinal del cannabis en México, enterrada desde la década de 1920, se restableció, pero no como consecuencia del trabajo legislativo, más bien este uso se relegitimó al amparo y bajo la tutela del Poder Judicial. Como fuese, este uso medicinal no abarcaba a la población en general, sino solamente a casos particulares amparados judicialmente.

En segundo lugar, también en el año 2015, la Suprema Corte concedió un recurso de amparo -es decir, otorgó la protección de la justicia federal ante la violación de un derecho fundamental tutelado por la Constitución Política-, a la Sociedad Mexicana de Autoconsumo Responsable y Tolerante (SMART), una asociación civil que en 2013 había solicitado permisos para consumir marihuana con fines lúdicos o recreativos. Más allá de la decisión de la Suprema Corte de amparar a esta asociación civil, lo que realmente sorprendió fueron las razones ulteriores para tal decisión: a saber, que el sistema de prohibición administrativa del cannabis es inconstitucional por ser violatorio del derecho fundamental al "libre desarrollo de la personalidad" (Suprema Corte de Justicia de la Nación de México, 2015: 5).

Entre 2015 y 2018, la Suprema Corte resolvió cuatro amparos más con el mismo argumento, lo que en el derecho mexicano consolida una jurisprudencia con efectos generales a la población, vinculante para todos los jueces del Poder Judicial de la Federación. Además, esta jurisprudencia obligó al Poder Legislativo a realizar las reformas al marco jurídico vigente para acatar la jurisprudencia emitida por la Suprema Corte. Estas reformas por 
parte del Poder Legislativo son un asunto aún pendiente cuando se terminó de escribir este artículo.

En tercer lugar y por último, mientras la discusión sobre la importación legal de СвD estaba en la palestra y mientras la jurisprudencia de la Suprema Corte ya avalaba el uso recreativo del cannabis, en 2016 la Secretaría de Gobernación y la Secretaría de Salud convocaron al "Debate Nacional sobre el Uso de la Marihuana”, en el que participaron diversas voces dentro del ámbito científico (Pérez Ricart, en prensa). Aunque el argumento del acceso a la salud estuvo presente en aquel debate, resulta curioso que predominase la idea de que avanzar hacia la descriminalización del uso médico del cannabis -y eventualmente lúdico e industrial- podría tener algún impacto positivo frente al clima de violencia homicida en México, una relación para la que no hay evidencia documental disponible.

Como resultado de ese debate, desde el Poder Ejecutivo se propuso en abril de 2016 una iniciativa que implicó importantes avances con respecto al reconocimiento de las virtudes terapéuticas y medicinales del cannabis. Se establecía que "existe la conveniencia y necesidad de tener acceso a todos los recursos terapéuticos que derivan del desarrollo científico y médico a nivel mundial, entre los que se encuentran aquellos desarrollados a partir de cannabis sativa, índica, americana o marihuana" (Peña Nieto, 2016: 963). En concreto, se promovía modificar la ley para permitir "todo acto relacionado con la cannabis sativa, índica y americana o marihuana, o su resina, exclusivamente con fines científicos y médicos", así como suprimir la prohibición para la preparación y consumo general del tetrahidrocannabinol o THC-principal componente psicoactivo del cannabis- (Peña Nieto, 2016). Además, entre otras modificaciones, se proponía la elevación del umbral de posesión para consumo personal a 28 gramos.

La iniciativa de Peña Nieto se oficializó una semana después de celebrada la Sesión Especial de la Asamblea General de la ONU, convocada por los gobiernos de Guatemala, Colombia y México en 2012 con el objetivo de reconceptualizar la forma en que las administraciones de la región abordan el "Problema mundial de las drogas". En aquella cumbre, acaso obligado por la coyuntura, el presidente Peña Nieto abogó por políticas de drogas planteadas desde una perspectiva de derechos humanos. A pesar de tratarse de un avance importante, el consenso general fue que la propuesta realizada por el presidente Peña Nieto había desaprovechado la oportunidad clave para avanzar hacia la legalización integral del cannabis (Madrazo Lajous, 2017; Pérez Correa y Ruíz Ojeda, 2018).

Resultado de la propuesta de Peña Nieto, en abril de 2017, por abrumadora mayoría en la Cámara de Diputados -362 votos a favor, 7 en con- 
tra y 11 abstenciones- se aprobó un dictamen que autorizaba el uso y prescripción médica del cannabis, así como su investigación científica y el desarrollo de una industria nacional de productos medicinales derivados de esta planta (Cámara de Diputados de México, 2017). Con esta votación a favor se reconoció el valor terapéutico del CBD y del THC y se ordenó su reclasificación dentro del régimen de sustancias controladas. Asimismo, se puntualizó que mientras los productos medicinales con menos de $1 \%$ de THC requerirán de receta médica estándar, aquellos con más de 1\% de THC requerirán de receta especial. El dictamen aprobado también estableció que la "siembra, cultivo y cosecha" de plantas de marihuana no sería punible siempre y cuando esas actividades se llevaran a cabo "con fines médicos y científicos en los términos y condiciones de la autorización que para tal efecto emita el Ejecutivo federal". Asimismo, el dictamen ordenaba al Consejo de Salubridad General que, "a partir de los resultados de la investigación nacional", diese "a conocer el valor terapéutico o medicinal que lleve a la producción de los fármacos que se deriven de la cannabis sativa, índica y americana o marihuana y sus derivados, para garantizar la salud de los pacientes" (Cámara de Diputados de México, 2017). Finalmente, se ordenó a la Secretaría de Salud diseñar y ejecutar políticas públicas que normen alrededor del cannabis como medicamento y para ello se requirió la elaboración de un reglamento especializado. Este reglamento aún no ha sido promulgado, dejando la aprobación del cannabis como medicamento en un limbo jurídico, en un claro ejemplo de negligencia legislativa.

El decreto que avala -solamente en la letra de la ley-el uso medicinal del cannabis fue publicado en junio de 2017 en el Diario Oficial de la Federación. Sin embargo, el proceso de ejecución de la reforma ha sido lento y complejo. Al momento de terminar de escribir este artículo, la Secretaría de Salud continuaba sin publicar el reglamento necesario para conocer las directrices del comercio local, exportación e importación de los productos, así como la forma en que se permitirá el cultivo con fines médicos y científicos. En ese contexto, el próximo reglamento -que debe de publicarse durante el 2020 por orden de la Suprema Corte- podría solamente autorizar la importación de medicamentos producidos por laboratorios extranjeros y la explotación farmacéutica en México, esto mediante complejos y costosos protocolos de investigación. Eso significaría que el derecho a la salud se dejaría a la deriva como un privilegio para aquellos que puedan pagarlo.

Pero la incertidumbre jurídica no es exclusiva a los usos medicinales del cannabis. Como se mencionó anteriormente, la regulación de la marihuana para fines lúdicos y recreativos también se encuentra en una zona gris e 
incierta. Así, las interrogantes radican no solo en cómo se elaborará y cuándo se promulgará el reglamento para activar de facto los usos medicinales del cannabis en México; sino también en cómo acatarán el Poder Legislativo y el Poder Ejecutivo la orden de la Suprema Corte -emitida en noviembre de 2019- para superar la inconstitucionalidad de la prohibición del cannabis con usos lúdicos y recreativos. ${ }^{[10]}$ Detrás de ambas interrogantes se evidencia un factor común: la incertidumbre sobre cómo el Estado mexicano diseñará y aplicará una política pública en torno al cannabis basada en evidencia científica.

\section{CONCLUSIONES}

Este artículo tuvo dos objetivos centrales. Por un lado, examinar la historia de los usos terapéuticos y medicinales del cannabis en México. Por el otro, exponer el proceso histórico que desembocó en la reactivación del debate sobre el tema en la última década. Para lograr el primer objetivo, se documentó la manera en que la planta cannabis y sus derivados fueron incorporados en la farmacéutica mexicana durante el XIx y principios del xx. En la primera sección de este artículo se mostró que la evidencia científica de la época respaldaba algunos beneficios de la marihuana, y que la planta y varios de sus derivados fueron avalados como medicamentos por los saberes médicos y por la legislación mexicana durante la segunda mitad del siglo XIx. Empero, eso no evitó que la prensa y los debates médicos comenzaran a resaltar las características negativas o el potencial efecto nocivo de la marihuana, dinámica que cristalizó en las primeras prohibiciones.

Desde la perspectiva contemporánea, el objetivo de las primeras prohibiciones no es del todo claro. Sin embargo, al analizar el Código Penal de 1871 y los subsecuentes Códigos de Salubridad de 1891, 1894 y 1902, al comprender el contexto social en el que emergieron y al enlistar las sustancias controladas durante ese período, es posible argumentar que, en materia de prohibición de drogas, las autoridades mexicanas legislaron tratando, primero, de cuidar la calidad de las sustancias que se vendían en farmacias $\mathrm{y}$, segundo, de aminorar el consumo no medicinal de estas -el cual desde la perspectiva médico-legal podía derivar en abuso o toxicomanía-. Durante este primer período histórico, la brecha entre la evidencia científica disponible y la codificación legal del cannabis en México fue, más bien, corta.

[10] Para un resumen, véase Ramírez y Gutiérrez (2019). 
Las primeras regulaciones y prohibiciones del cannabis fueron resultado de un análisis consecuente de la evidencia científica disponible; sin embargo, durante la segunda mitad del siglo XIx fue posible percibir contradicciones en las disposiciones oficiales sobre la concepción de la marihuana: la brecha entre evidencia y disposiciones legales comenzó a ampliarse. En ese contexto, la segunda sección se expuso el proceso mediante el cual a lo largo del siglo xx la marihuana dejó de ser considerada por los discursos oficiales un medicamento, para convertirse en una droga prohibida y su uso en un "Delito contra la salud". Además de exponer el establecimiento del paradigma prohibitivo en los debates constitucionales de 1917, la segunda sección analizó la promulgación del "Decreto para prohibir el cultivo y comercio de plantas y sustancias que degeneren la raza" de 1920, la promulgación de los Códigos Penales de 1929 y 1931, así como el resto de las disposiciones prohibitivas que continuaron negando los usos medicinales del cannabis en México. En esta sección también se hizo notar la paradójica ausencia de debate alrededor del cannabis entre las élites médicas del país durante prácticamente todo el siglo xx.

Finalmente, con respecto al segundo objetivo de este artículo, la tercera sección sintetizó el punto en el que desembocó el proceso histórico en torno al cannabis en México. Se trata de un estadio que actualmente enmarca un dinámico debate legislativo sobre los usos médicos y lúdicos de la marihuana. Este debate, en función de evidencia científica y cierta congruencia jurídica, busca reivindicar el estatus jurídico de la planta, para lo cual se busca regular sanitariamente los usos medicinales del cannabis y se busca descriminalizar e incluso también regular administrativamente sus usos lúdicos.

Se mostró cómo el lento pero progresivo avance en favor del reconocimiento de las propiedades terapéuticas y medicinales del cannabis durante el siglo XXI en México parece dirigirse a una reivindicación que, si bien había ignorado estos usos por décadas, de algún modo recupera la legitimación de esta planta perceptible desde el siglo XIX y principios del xx. Con respecto a este aceleramiento del proceso de asimilación del cannabis con potencial médico a lo largo de la última década, es interesante que a escala global los cambios también son evidentes: los diversos pronunciamientos de la Organización Mundial de la Salud a partir del 2017 en torno al alto potencial terapéutico del СвD; la decisión de otros países del continente por adoptar legislaciones menos prohibitivas frente al cannabis -siendo la de Uruguay un caso paradigmático- y la rápida consolidación en Estados Unidos y Canadá de una industria farmacéutica basada en cannabis ha generado la idea entre las élites académicas, políticas y económicas de que México está perdiendo la oportunidad de situarse como "potencia de la 
industria farmacéutica mundial” (Madrazo Lajous, 2017). En ese contexto, la opinión pública mexicana, normalmente afín a la prohibición, se ha transformado reconociendo las virtudes medicinales del cannabis (Ramírez, 2019). La actual coyuntura se presenta como el espacio adecuado para que la discusión avance en función de evidencia científica de vanguardia y además, de manera simultánea, esta coyuntura se erige como el terreno propicio para que en México el desprecio a los usos médicos del cannabis sea ya parte del pasado.

\section{REFERENCIAS BIBLIOGRÁFICAS}

Academia Farmacéutica de la Capital de la República (1846), Farmacopea mexicana formada y publicada por la Academia Farmacéutica de la Capital de la República, México, Imprenta de Manuel de la Vega.

Agostoni, C. (1999), "Médicos científicos y médicos ilícitos en la Ciudad de México durante el Porfiriato", Estudios de Historia Moderna y Contemporánea de México, No 19, pp. 13-33.

— (2003), Monuments of Progress: Modernization and Public Health in Mexico City, 1876-1910, Calgary, University of Calgary Press.

Aréchiga Córdoba, E. (2007), "Educación, propaganda o 'dictadura sanitaria'. Estrategias discursivas de higiene y salubridad públicas en el México Posrevolucionario", Estudios de Historia Moderna y Contemporánea de México, No 33, pp. 57-88.

Cámara de Diputados de México (2017), "Conoce Pleno tres dictámenes; uno de ellos, en materia de uso medicinal de la cannabis", Boletín, No 3.572, 27 de abril. Disponible en: <http://www5.diputados.gob.mx/index.php/ esl/Comunicacion/Boletines/2017/Abril/27/3572-Conoce-Pleno-tresdictamenes-uno-de-ellos-en-materia-de-uso-medicinal-de-la-cannabis>.

Campos, I. (2012), Home Grown: Marijuana and the Origins of Mexico's War on Drugs, Chapel Hill, The University of North Carolina Press.

Carrancá y Rivas, R. y R. Carrancá y Trujillo (1976), Código Penal anotado (sexta edición), México, Editorial Porrúa.

Comisión Nacional para la Celebración del Sesquicentenario de la Proclamación de la Independencia Nacional y del Cincuentenario de la Revolución Mexicana (1960), Diario de los Debates del Congreso Constituyente 19161917, México, Talleres Gráficos de la Nación.

Conde Rodríguez, E. de G. (2007), "Iniciativa con proyecto de decreto, que reforma y adiciona diversas disposiciones del Código Penal Federal y del Código Federal de Procedimientos Penales", Gaceta Parlamentaria, vol. XI, 
No 2.391, 27 de noviembre. Disponible en: <http://gaceta.diputados.gob. $\mathrm{mx} /$ Gaceta/60/2007/nov/20071127-I.html\#Ini20071127-8>.

Corona Ojeda, G. (2019), Breve historia de la guerra contra el narcotráfico y la regulación del cannabis en México, Aguascalientes, Centro de Investigación y Docencia Económicas.

Dawson, A. (2018), The Peyote Effect: From the Inquisition to the War on Drugs, Oakland, University of California Press.

Departamento de Salubridad Pública de México (1920), "Disposiciones sobre el cultivo y comercio de productos que degeneren la raza", Diario Oficial de la Federación, vol. xIv, No 63, pp. 1189-1190, 15 de marzo.

_ (1926a), "Código Sanitario de los Estados Unidos Mexicanos", Diario Oficial de la Federación, vol. xxxvi, No 31, pp. 579-599, 8 de junio.

_ (1926b), "Código Sanitario de los Estados Unidos Mexicanos", Diario Oficial de la Federación, vol. xxxvi, No 32, pp. 617-631, 9 de junio.

Durán, F. (2000), Bitácora Médica del Dr. Falcón. La medicina y la farmacia en el siglo XIX, México, Plaza y Valdés / Universidad La Salle.

Durán, J. I. (1846), "Memoria de los trabajos que ha desempeñado el consejo superior de salubridad el año 1845", El Republicano, vol. I, No 36, pp. 1-2, 5 de abril.

El Consultor (1898), "Memorándum”, El Consultor, 15 de noviembre.

El Diario (1908a), "Descúbrese un expendio de marihuana. Encuéntranse arrobas de ese veneno", El Diario, vol. vI, No 641, p. 4, 17 de julio.

- (1908b), "Se debe perseguir la marihuana. Las circunstancias la hace muy peligrosa”, El Diario, vol. vi, No 698, p. 4, 11 de septiembre.

El Heraldo de México (1919), El Heraldo de México, 10 de octubre.

El Imparcial (1908a), "Los habitantes de la capital eran enloquecidos por la marihuana”, El Imparcial, vol. xxv, No 4.308, pp. 1 y 8, 17 de julio.

(1908b), "El envenenador capturado se dice benefactor público", $E l$ Imparcial, vol. xxv, No 4.311, pp. 1 y 7, 20 de julio.

__ (1908c), "Las misas negras de la marihuana", El Imparcial, vol. xxv, № 4.314, pp. 1 y 8,23 de julio.

— (1867a), "Cigarros indios de cannabis indica Grimault y Cia, farmacéuticos en París”, El Siglo Diez y Nueve, séptima época, vol. 24, № 5, p. 4, 19 de julio.

(1867b), "Cigarros indios de cannabis indica Grimault y Cia, farmacéuticos en París", El Siglo Diez y Nueve, séptima época, vol. 24, No 19, p. 4, 2 de agosto.

(1867c), "Cigarros indios de cannabis indica Grimault y Cia, farmacéuticos en París”, El Siglo Diez y Nueve, séptima época, vol. 24, No 26, p. 4, 9 de agosto. 
(1867d), "Cigarros indios de cannabis indica Grimault y Cia, farmacéuticos en París", El Siglo Diez y Nueve, séptima época, vol. 24, No 33, p. 4, 16 de agosto.

- (1868), "Cigarros indios de cannabis indica Grimault y Cia, farmacéuticos en París”, El Siglo Diez y Nueve, séptima época, vol. 25, No 434, p. 4, 20 de septiembre.

— (1869), "Cigarros indios de cannabis indica Grimault y Cia, farmacéuticos en París”, El Siglo Diez y Nueve, séptima época, vol. 26, No 64, p. 4, 5 de marzo.

Elegancia (1925), Elegancia, 1 de marzo.

Enciso, F. (2015), Nuestra Historia Narcótica. Pasajes para (re)legalizar las drogas en México, México, Debate.

Gobierno de México (1871), Código Penal para el Distrito Federal y territorio de la Baja-California sobre delitos del fuero común y para toda la República sobre delitos contra la Federación, México, Edición Oficial.

Herrera, J. (2006), "Critican rechazo de Eu a despenalizar drogas", El Universal, 12 de mayo. Disponible en: <https://archivo.eluniversal.com. $\mathrm{mx} / \mathrm{nacion} / 138259 . \mathrm{html}$.

La Medicina Cientifica (1895), "El extracto acuoso de cannabis indica, sus efectos terapéuticos", La Medicina Científica, vol. viII, No 22, p. 383, 15 de diciembre.

La Sociedad (1867a), "Cigarros indios de cannabis indica Grimault y Cia, farmacéuticos en París", La Sociedad, tercera época, vol. v, No 1.333, p. 4, 7 de marzo.

_ (1867b), "Cigarros indios de cannabis indica Grimault y Cia, farmacéuticos en París”, La Sociedad, tercera época, vol. v, No 1.340, p. 4, 14 de marzo.

- (1867c), "Cigarros indios de cannabis indica Grimault y Cia, farmacéuticos en París", La Sociedad, tercera época, vol. v, No 1.347, p. 4, 21 de marzo.

— (1867d), "Cigarros indios de cannabis indica Grimault y Cia, farmacéuticos en París", La Sociedad, tercera época, vol. v, No 1.354, p. 4, 28 de marzo.

Madrazo Lajous, A. (2017), "La oportunidad desperdiciada por México: ser una potencia en la industria farmacéutica cannábica”, Vice, 19 de abril. Disponible en: <https://www.vice.com/es_latam/article/4x9x5j/la-oportunidaddesperdiciada-por-mexico-ser-una-potencia-en-la-industria-farmaceuticacannabica>.

Martín Martín, C., J. Valverde y P. de Montenegro (1995), La farmacia en la América Colonial: el arte de preparar medicamentos, Granada, Universidad de Granada / Hermandad Farmacéutica Granadina. 
Meza Fonseca, E. y H. Lara González (2001), "Ilícitos contra la salud. ¿Modalidades o delitos?”, Revista del Instituto de la Judicatura Federal, No 8, pp. 193-234.

Monin, E. (1925), "La gripa intestinal”, El Informador, vol. XvII, No 1.662, p. 3, 25 de abril.

Monnet, Dr. (1893), "La cuestión de los Callos", El Tiempo, vol. x, № 2.832, p. 1,8 de febrero.

Muñoz, A. (2018), "La Cofepris ya liberó 331 permisos para importar medicamentos con base de Cannabis", La Jornada, 20 de abril. Disponible en: $<$ https://www.jornada.com.mx/2018/04/20/sociedad/035n1soc>.

Noriega, J. M. (1902), Curso de historia de drogas, México, Oficina Tipográfica de la Secretaría de Fomento.

Ochoa Serrano, Á. (1980), "Las investigaciones de Crescencio García sobre medicina popular", Relaciones. Estudios de Historia y Sociedad, vol. 1, No 4, pp. 76-99.

Oliva, L. (1853), Lecciones de farmacología: por el catedrático del ramo en la universidad de Guadalajara, México, Tipografía de Rodríguez.

Olvera, J. (1897), "Expendio libre de yerbas medicinales, de venenos y otras drogas peligrosas", La Farmacia, vol. VI, No 12, pp. 265-274, 15 de diciembre.

Peña Nieto, E. (2016), "Iniciativa de Decreto por el que se reforman, adicionan, y derogan diversas disposiciones de la Ley General de Salud y se reforma el párrafo tercero del artículo 195 del Código Penal Federal”, Diario de los Debates, LXIII Legislatura, vol. I, No 26, pp. 961-972, 21 de abril. Disponible en: <http://infosen.senado.gob.mx/content/sp/dd/content/ cale/diarios/63/1/SPO/PDF-WEB/SPO_No26_21_ABR_2016.pdf>.

Pérez, G. (1886), La marihuana: Breve estudio sobre esta planta, tesis para examen profesional de medicina, México, Facultad de Medicina de México.

Pérez Correa, C. (2013), “¿Qué ha pasado con la Ley de Narcomenudeo?”, Animal Político, 7 de agosto. Disponible en: <https://www.animalpolitico. com/no-hay-derecho/que-ha-pasado-con-la-ley-de-narcomenudeo/ \#axzz2bxd479IO>.

— - y A. Ruíz Ojeda (2018), Marihuana en México: el peso de la prohibición, Aguascalientes, Centro de Investigación y Docencia Económicas.

Pérez Correa, C., R. Uprimny y S. Chaparro (2016), "Regulation of Possession and the Criminalisation of Drug Users in Latin America”, en Collins, J. y A. Soderholmm (eds.), After the Drug Wars, report of the LSE Expert Group on the Economics of Drug Policy, Londres, The London School of Economics and Political Science, pp. 30-39. 
Pérez Montfort, R. (2016), Tolerancia y probibición: aproximaciones a la historia social y cultural de las drogas en México (1840-1940), México, Debate.

Pérez Ricart, C. (2018), "U.s. pressure and Mexican anti-drugs efforts from 1940 to 1980: Importing the war on drugs?", en Pansters, W. G., B. T. Smith, y P. Watt (eds.), Beyond the Drug War in Mexico: Human rights, the public sphere and justice, Oxford, Routledge, pp. 33-52.

- (en prensa), "Mexico and Central America: Flexibility and Frameworks", en Idler, A. y J. Garzón Vergara (eds.), Transforming the War on Drugs. Warriors, Victims and Vulnerable Regions, Londres, Hurst Publishers.

Planchon, G. (1895), Les drogues simples d'origen végétales, París, Octave Dion. Ponce Alcocer, M. (2004), Algunas enfermedades, remedios y tratamientos terapéuticos en el México del siglo XIX, México, Universidad Iberoamericana.

Ramírez, S. (2019), "Polariza a mexicanos regular cannabis, revela encuesta de instituto del Senado", La Razón, 30 de octubre. Disponible en: <https:// www.razon.com.mx/mexico/polariza-a-mexicanos-regular-cannabis-revelaencuesta-de-instituto-del-senado/>.

— y V. Gutiérrez (2019), "Cuenta regresiva: el dictamen de cannabis", Nexos, 17 de octubre. Disponible en: <https://www.nexos.com.mx/?p=45311>.

Rodríguez de Romo, A. y M. Rodríguez Pérez (1998), "Historia de la salud pública en México: siglos xIx y xx”, História, Ciências, Saúde-Manguinhos, vol. 5, No 2, pp. 293-310.

Schievenini, J. (2018), "La criminalización del consumo de marihuana en México (1912-1961)", tesis de doctorado, México, unam.

Secretaría de Gobernación de México (1903), Código Sanitario de los Estados Unidos Mexicanos, México, Herrero Hermanos.

(1947), "Decreto que reforma y adiciona los artículos 193, 194 y 197 del Código Penal para el Distrito y Territorios Federales en materia del Fuero Común y para toda la República en materia del Fuero Federal", Diario Oficial de la Federación, vol. CLxv, No 12, pp. 2-3, 14 de noviembre.

(1968), "Decreto que reforma los Artículos 15, 85, 193, 194, 195, 196, 197, 198, 199, 201, 306, 309 y 387; modificación del nombre de Capítulo Primero, Título Séptimo, Libro Segundo; y adición del Artículo 164 Bis del Código Penal para el Distrito y Territorios Federales en materia de Fuero Común y para toda la República en materia de Fuero Federal", Diario Oficial de la Federación, vol. CCLxxxviI, No 7, pp. 2-4, 8 de marzo. (1978), "Decreto de reformas al Código Penal para el Distrito Federal en Materia del Fuero Común y para toda la República en Materia del Fuero Federal, en sus artículos 85, 194, 195, 196, 197 y 198”, Diario Oficial de la Federación, vol. CCCLI, No 27, pp. 3-4, 8 de diciembre. 
Secretaría de Salubridad y Asistencia de México (1974), "Decreto de Reformas al Código Penal para Distrito Federal en materia de Fuero Común y para toda la República en materia de Fuero Federal; al Código Sanitario de los Estados Unidos Mexicanos, en relación con estupefacientes y psicotrópicos y al Artículo 41 del Primer Ordenamiento", Diario Oficial de la Federación, vol. cCCXXviı, No 41, pp. 23-26, 31 de diciembre.

Senado de la República de México (2020), "Dictamen de las Comisiones Unidas de Justicia, Salud y Estudios Legislativos con opinión de la Comisión de Seguridad Pública, por el que se expide la ley para la regulación del cannabis y reforma y adiciona diversas disposiciones de la Ley General de Salud y del Código Penal Federal", Senado de la República. Regulación del cannabis. Disponible en: <https://cannabis.senado.gob. $\mathrm{mx} /$ images/pdf/ADLRC.pdf $>$.

Smith, B. (2016), "Drug Policies in Mexico, 1900-1980", en Labate, B., C. Cavnar y T. Rodrigues (eds.), Drug Policies and the Politics of Drugs in Latin America, Cham, Springer, pp. 33-52.

(2019), "The Dialectics of Dope: Leopoldo Salazar Viniegra, the Myth of Marijuana, and Mexico's State Drug Monopoly”, en Wilson, S. (ed.), Prohibitions and Psychoactive Substances in History, Culture and Theory, Londres, Routledge, pp. 111-132.

Sociedad Farmacéutica Mexicana (1874), Nueva farmacopea mexicana (primera edición), México, Imprenta de Ignacio Escalante.

- (1884), Nueva farmacopea mexicana (segunda edición), México, Imprenta de Francisco Díaz de León.

- (1896), Nueva farmacopea mexicana (tercera edición), México, Oficina Tipográfica de la Secretaría de Fomento.

Suprema Corte de Justicia de la Nación de México (2015), Amparo en Revisión 237/2014, 4 de noviembre. Disponible en: <http://www2.juridicas. unam.mx/marihuana-caso-mexico/wp-content/uploads/2016/02/Sesionpublica-04-11-2015.pdf>.

Artículo recibido el 31 de diciembre de 2019. Aprobado para su publicación el 19 de marzo de 2020. 